\title{
Unusual Findings in Appendectomy: Experience in a Third Level Hospital with More than 1000 Specimens
}

\author{
L. V. Fuentes-Ernult ${ }^{*}{ }^{\circledR}$, , P. Gálvez-Castillejos ${ }^{1}$, A. A. Molina-Villena1 ${ }^{1}$ A. Carballo Zárate ${ }^{2}$, \\ J. B. Ivey-Miranda ${ }^{3}$, L. F. De Giau-Triulzi ${ }^{1}$, A. M. González-Chávez ${ }^{4}$ (i) \\ ${ }^{1}$ Department of Gastroenterology, Hospital Español de México, Mexico City, México \\ ${ }^{2}$ Department of Pathology, Hospital Español de México, Mexico City, México \\ ${ }^{3}$ Instituto Mexicano del Seguro Social, Mexico City, México \\ ${ }^{4}$ Department of Surgery, Hospital Español de México, Mexico City, México \\ Email: *lvfernult@gmail.com
}

How to cite this paper: Fuentes-Ernult, L.V., Gálvez-Castillejos, P., Molina-Villena, A.A., Carballo Zárate, A., Ivey-Miranda, J.B., De Giau-Triulzi, L.F. and González-Chávez, A.M. (2019) Unusual Findings in Appendectomy: Experience in a Third Level Hospital with More than 1000 Specimens. Surgical Science, 10, 377-384.

https://doi.org/10.4236/ss.2019.1011042

Received: May 29, 2019

Accepted: November 1, 2019

Published: November 4, 2019

Copyright (c) 2019 by author(s) and Scientific Research Publishing Inc. This work is licensed under the Creative Commons Attribution International License (CC BY 4.0).

http://creativecommons.org/licenses/by/4.0/

\begin{abstract}
Introduction and Aims: Acute appendicitis is a commonly established diagnosis in the approach of abdominal pain. It is usually due to an acute inflammatory process in the appendix. Nevertheless, there is a small percentage of cases due to non-frequent etiologies that are only identifiable based on histopathological analysis. The aim of this study was to determine the prevalence and characterization of these unusual findings. Materials and $\mathrm{Me}-$ thods: The present study was a cross-sectional study in a third-level hospital in Mexico City. Clinical information was collected from unusual findings in the histopathological analysis of 1018 appendectomy specimens between January 2012 and April 2017. Results: In total, 1018 appendectomy specimens were included. In 11 of those appendices (1.08\%), unusual findings compatible with appendicular tumors were identified. Carcinoid tumor found in the tip of the appendix was the most frequently reported finding. The muscular layer was affected in most cases; up to $25 \%$ of regional ganglia were invaded. Most of the patients presented with abdominal pain and clinical signs suggestive of acute appendicitis. The preferred approach for surgical treatment was laparoscopic. Discussion and Conclusion: The prevalence of unusual findings in our population was $1.08 \%$, with carcinoid tumors the most frequently established diagnosis among those (0.58\%), according to previously reported literature data.
\end{abstract}

\section{Keywords}

Carcinoid Tumor, Appendicitis, Unusual Finding 


\section{Introduction and Objectives}

Acute appendicitis is one of the main reasons for admission in daily clinical practice involving gastroenterologists and surgeons. Clinical presentation is characterized by abdominal pain, generally progressive and described as migratory, which usually starts in the epigastrium and migrates to the lower right quadrant. Until now, the only treatment that could be recommended with evidence was the surgical removal of the swollen appendix [1]. This condition is mainly caused by a mechanical obstruction of the appendix due to a fecalith or by proliferation of lymphoid tissue. Mucinous cystadenoma or mucocele, carcinoid tumor, granulomatous and parasitic diseases (Taenia and Ascaris) are also among unusual causes. Appendiceal tumors have typically been reported in less than 3\% of appendectomies and are rarely associated with particular clinical manifestations. They are generally incidental findings during abdominal surgery or in the histopathological examination of the resected specimen [2] [3].

Carcinoid tumor is the most common diagnosis of primary appendicular malignancy; it comprises approximately $60 \%$ of all cecal appendiceal tumors, and its incidence in appendectomized patients ranges from $0.30 \%$ to $2.27 \%$ [4] [5]. Limaiem et al. analyzed the histopathological findings of 1627 appendectomies. The most frequent incidental pathological findings were the presence of intestinal parasites, mucinous neoplasms of the appendix and neuroendocrine tumors [6]. In another retrospective study, 1237 appendectomies performed in a 4-year period were analyzed; the authors found that carcinoid tumors represent $0.4 \%$ of all appendectomies performed. They suggest that if the tumor measures less than $1 \mathrm{~cm}$, resection of the mesoappendix during the appendectomy should be done with no requirement of further adjuvant therapy [2].

Nearly all appendectomy patients have a favorable prognosis; however, it is important to know the incidence of unusual findings, mainly those related to tumors that could represent a less benign outcome. The purpose of the present study is to determine the prevalence of unusual findings and the histopathological characterization in our study population [7].

\section{Material and Methods}

We performed an observational, descriptive, transversal population study at Hospital Español de México between January 2012 and April 2017 with patients aged over 18 years who presented to the emergency room with abdominal pain suggestive of acute appendicitis and who were subjected to surgical treatment with appendectomy. Patients lacking complete medical history as well as definite histopathological diagnosis were excluded.

Demographic characteristics of the population with unusual findings were obtained from clinical records stored in the Hospital's medical file such as: age, gender, comorbidities, surgical background and findings during initial physical exam. Information regarding the surgical technique used was also obtained. The collected information was later summarized and presented in charts. 
Histopathological information related to appendectomy specimens, regarding histological subtype, location in the appendix, degree of differentiation, degree of local or distant invasion as well as need for follow-up, was collected from gastrointestinal pathology service files.

Categorical data were described with number and percentage, whereas continuous data were described using mean, standard deviation and median.

Because the main objective of the present study was to estimate the prevalence of unusual findings, percentage of this variable and its $95 \%$ confidence interval (CI) was determined. The Stata version 14 program was used for the statistical analysis (Stata Corp LP, College Station, TX).

\section{Results}

A total of 1018 appendectomy specimens were included. In this series, unusual findings are defined as causes of appendicitis other than fecaliths and lymphoid hyperplasia. Eleven unusual findings were assessed (prevalence of 1.08\%, CI 95\% $0.6 \%-1.9 \%)$. Between these, most of the patients were females $(n=9)$ with a mean age of $50.9 \pm 22.0$ years. Demographic characteristics showing personal pathological surgical and non-surgical background are presented in Table 1. Arterial hypertension was the most frequent comorbidity in three patients. Physical exploration at the time of admission was suggestive of acute abdomen in nearly all patients (Table 1 ).

The most frequent unusual finding in our population was carcinoid tumor, representing more than half of the cases. The most frequent location was at the tip of the appendix. As described in Table 2, tumors were approximately $1 \mathrm{~cm}$ and most of them involved the muscle layer; they were all well-differentiated tumors and less than $50 \%$ of them showed ganglion invasion. Clinical presentation in most patients was abdominal pain with clinical signs corresponding to acute appendicitis.

Regarding prognosis, long-term follow-up because of tumor features was not required for the majority of patients, whereas just one patient continued under oncological surveillance owing to an ovarian primary tumor. Another patient died owing to causes unrelated to the appendectomy or its findings.

Carcinoid tumors in our study population were of benign nature, well-differentiated, mostly located at the tip $(n=4)$ and without metastatic disease. None of the cases developed carcinoid syndrome. Prevalence of carcinoid tumor was $0.58 \%$; CI 95\% 0.26\% - 1.3\% (Table 3).

\section{Discussion and Conclusions}

Acute appendicitis diagnosis is mostly clinical. In our hospital, all surgically resected specimens are sent to the pathology department for their evaluation and diagnostic confirmation. The main goal of the present study was to determine the prevalence of unusual diagnostics that presented as abdominal pain with features suggesting acute appendicitis. 
Table 1. Demographic features of patients associated with unusual findings in histopathological analysis.

\begin{tabular}{|c|c|}
\hline Number of unusual findings & $\mathrm{n}=11$ \\
\hline Female & $\mathrm{n}=9(82 \%)$ \\
\hline Male & $\mathrm{n}=2(18 \%)$ \\
\hline Age (years) & $50.9 \pm 22.0$ \\
\hline \multicolumn{2}{|l|}{ Personal pathological non-surgical background } \\
\hline Hypertension & $\mathrm{n}=3$ \\
\hline Cerebrovascular events & $\mathrm{n}=1$ \\
\hline Secondary hypothyroidism & $\mathrm{n}=1$ \\
\hline Epidermoid carcinoma & $\mathrm{n}=1$ \\
\hline Osteopenia & $\mathrm{n}=1$ \\
\hline \multicolumn{2}{|l|}{ Personal pathological surgical background } \\
\hline Cesarean & $\mathrm{n}=2$ \\
\hline Total abdominal hysterectomy & $\mathrm{n}=1$ \\
\hline Laparoscopic cholecystectomy & $\mathrm{n}=2$ \\
\hline \multicolumn{2}{|l|}{ Physical Exam } \\
\hline McBurney/Rovsing's sign/Peritoneal irritation & $\mathrm{n}=8$ \\
\hline Abdominal mass & $\mathrm{n}=3$ \\
\hline \multicolumn{2}{|l|}{ Admission diagnosis } \\
\hline Acute appendicitis & $\mathrm{n}=8$ \\
\hline Right adnexal mass & $\mathrm{n}=3$ \\
\hline \multicolumn{2}{|l|}{ Timing of the unusual diagnosis with respect to surgery } \\
\hline Before surgery & $\mathrm{n}=4$ \\
\hline After surgery & $\mathrm{n}=7$ \\
\hline
\end{tabular}

The medical literature indicates that appendiceal tumors represent $3 \%$ of the causes of acute appendicitis, and $60 \%$ of them are cecal carcinoid tumors. According to the literature, the incidence of carcinoid tumors in appendectomy patients is approximately $0.3 \%-2.7 \%$. In the present study, the prevalence of unusual findings was $1.08 \%$, and carcinoid tumor was the most common among them with an incidence of $0.58 \%$, corresponding to data reported by K. W. Ma et al. [8].

Almost all tumors were found at the tip of the appendix, with an average size of $1 \mathrm{~cm}$ and involving muscular layer. All tumors were well differentiated; even when some of them showed perineural involvement, surgical and medical decisions were not changed, denoting that all tumors found during surgery had, in general, benign features that implied good prognosis. Clinical presentation among these patients was acute appendicitis, similar to that reported by Sevgi Buyokbese et al. [9]. In all cases, the diagnosis was confirmed using histopathological study. 
Table 2. General features of unusual findings in appendectomy specimens.

\begin{tabular}{|c|c|}
\hline Diagnostics observed & \\
\hline Carcinoid tumor & $\mathrm{n}=6$ \\
\hline Mucinous tumor & $\mathrm{n}=3$ \\
\hline Metastasis & $\mathrm{n}=1$ \\
\hline Invasive adenocarcinoma & $\mathrm{n}=1$ \\
\hline \multicolumn{2}{|l|}{ Location in the appendix } \\
\hline Tip & $\mathrm{n}=7$ \\
\hline Distal third & $\mathrm{n}=3$ \\
\hline Proximal third & $\mathrm{n}=1$ \\
\hline Average size & $0.96 \pm 1.04 \mathrm{~cm}$ \\
\hline \multicolumn{2}{|l|}{ Depth of invasion } \\
\hline Muscular layer & $\mathrm{n}=6$ \\
\hline Mesoappendix & $\mathrm{n}=3$ \\
\hline Serous layer & $\mathrm{n}=1$ \\
\hline Not assessed margins & $\mathrm{n}=1$ \\
\hline \multicolumn{2}{|l|}{ Degree of differentiation } \\
\hline Well-differentiated & $\mathrm{n}=11$ \\
\hline \multicolumn{2}{|l|}{ Lymphatic ganglion invasion } \\
\hline Present & $\mathrm{n}=5$ \\
\hline Absent & $\mathrm{n}=6$ \\
\hline \multicolumn{2}{|l|}{ Perineural permeation } \\
\hline Present & $\mathrm{n}=2$ \\
\hline Absent & $\mathrm{n}=9$ \\
\hline \multicolumn{2}{|l|}{ First approach } \\
\hline Laparoscopic appendectomy & $\mathrm{n}=9$ \\
\hline Exploratory laparotomy + appendectomy & $\mathrm{n}=1$ \\
\hline Exploratory laparotomy + right oophorectomy + appendectomy & $\mathrm{n}=1$ \\
\hline \multicolumn{2}{|l|}{ Follow-up } \\
\hline Not necessary & $\mathrm{n}=9$ \\
\hline Deceased & $\mathrm{n}=1$ \\
\hline Oncological follow-up & $\mathrm{n}=1$ \\
\hline
\end{tabular}

The calculated risk of metastasis for tumors smaller than $1 \mathrm{~cm}$ is 0 ; therefore, they can be managed only with appendectomy. However, metastasis risk increases to $85 \%$ in tumors larger than $2 \mathrm{~cm}$, and these tumors should be handled with hemicolectomy [8]. All cases in our study were approached with laparoscopic appendectomy as the initial procedure. Exploratory laparotomy and right oophorectomy were performed in one patient, owing to a histopathological diagnostic found during the study. 
Table 3. Carcinoid tumors found in our study population.

\begin{tabular}{cl}
\hline Carcinoid tumor-degree of differentiation & $\mathrm{n}=6$ \\
\hline Well-differentiated & $\mathrm{n}=6$ \\
\hline Location in the appendix & $\mathrm{n}=2$ \\
\hline Distal third & $\mathrm{n}=4$ \\
Tip & \\
\hline Clinical presentation & $\mathrm{n}=6$ \\
\hline Acute appendicitis & $\mathrm{n}=0$ \\
Carcinoid histological markers & $\mathrm{n}=6$ \\
Mitosis 1/High-power field (HPF) & $\mathrm{n}=6$ \\
Index ki 67 $<5 \%$ & \\
\hline
\end{tabular}

The reported prevalence of mucinous tumors in appendectomies ranges from $0.2 \%$ to $0.4 \%$. In the present study, a prevalence of $0.29 \%$ was demonstrated, all of them with low-degree and non-metastatic tumors, similar to findings reported in other studies.

Other diagnoses reported in literature and also found in our study are gynecological pathologies such as endometriosis or malignant infiltration; such incidence is reported to be up to $5.5 \%$. In our study, only one patient was found to have an ovarian adenocarcinoma.

The most frequent benign causes reported in some studies and bibliographic reviews are idiopathic granulomatous appendicitis and Crohn's disease. Other factors such as dysplastic change, hyperplastic polyps and eosinophilic granulomas have been the reported etiology in case reports [10]. The present study did not obtain these findings.

Certain infectious agents, mainly parasites and Mycobacterium tuberculosis, have also been reported in other studies as a common differential diagnosis for acute appendicitis, depending on the studied population. In one literature review, the authors found 1366 cases defined as "unusual findings" of acute appendicitis, of which 34 (2.5\%) corresponded to tuberculosis infection [10]. Studies involving large series of cases reported that the incidence of parasites in appendectomy specimens is $1.2 \%$. Enterobius vermicularis, Ascaris lumbricoides, Schistosoma spp. and Taenia spp. are common [11]. None of these causes was found in our report.

With respect to the long-term follow-up of the patients owing to size and degree of differentiation of surgical specimens, nine of them did not require it, one died due to causes unrelated to the initial diagnosis and in one subject, follow-up data were not obtained.

Finally, data reported in the present study is relevant enough to advise, emphasize and promote multidisciplinary interaction among gastroenterologists, surgeons and pathologists, in order to encourage histopathological examination of all appendectomy specimens. This becomes particularly relevant not only for 
the high prevalence of abdominal pain as a reason for inpatient or outpatient consultation in gastroenterology but also because appendicitis etiology appears to be unrecognizable based only on clinical presentation. More clinical attention and better understanding of etiology would facilitate identification of patients who require a strict follow-up as well as a multidisciplinary approach in agreement with the final diagnostic.

Clinical manifestations compatible with acute abdomen suggesting appendicitis as well as the data on prevalence of unusual findings in appendectomy specimens in our study is similar to what has been reported in international literature. We would like to emphasize the relevance of clinical correlation with histopathological study to determine not only the cause but also the nature and definite etiology of appendicitis, thus offering better therapeutic options to our patients.

\section{Conflicts of Interest}

The authors declare no conflicts of interest regarding the publication of this paper.

\section{References}

[1] Yilmaz, M., Akbulut, S., Kutluturk, K., et al. (2013) Unusual Histopathological Findings in Appendectomy Specimens from Patients with Suspected Acute Appendicitis. World Journal of Gastroenterology, 19, 4015.

https://doi.org/10.3748/wjg.v19.i25.4015

[2] Tchana-Sato, V., Detry, O., Polus, M., et al. (2006) Carcinoid Tumor of the Appendix: A Consecutive Series from 1237 Appendectomies. World Journal of Gastroenterology, 12, 6699-6701. https://doi.org/10.3748/wjg.v12.i41.6699

[3] Suárez-Grau, J.M., García-Ruiz, S., Rubio-Chavez, C., et al. (2014) Tumores carcinoides apendiculares. Evaluación de los resultados a largo plazo en un hospital de tercer nivel. Cirugía y Cirujanos, 82, 142-149.

http://www.redalyc.org/articulo.oa?id=66231034003

[4] Shapiro, R., Eldar, S., Sadot, E., et al. (2010) The Significance of Occult Carcinoids in the Era of Laparoscopic Appendectomies. Surgical Endoscopy, 24, 2197-2199. https://doi.org/10.1007/s00464-010-0926-0

[5] Watanabe, H., Fujimoto, T., Kato, Y., et al. (2016) Acute Appendicitis with a Neuroendocrine Tumor G1 (Carcinoid): Pitfalls of Conservative Treatment. Clinical Journal of Gastroenterology, 9, 203-207. https://doi.org/10.1007/s12328-016-0660-9

[6] Limaiem, F., Arfa, N., Marsaoui, L., et al. (2015) Unexpected Histopathological Findings in Appendectomy Specimens: A Retrospective Study of 1627 Cases. Indian Journal of Surgery, 77, 1285-1290. https://doi.org/10.1007/s12262-015-1278-8

[7] Amr, B., Froghi, F., Edmond, M., et al. (2015) Management and Outcomes of Appendicular Neuroendocrine Tumours: Retrospective Review with 5-Year Follow-Up. European Journal of Surgical Oncology, 41, 1243-1246. https://doi.org/10.1016/j.ejso.2015.06.010

[8] Cakar, E., Bayrak, S., Bektas, H., et al. (2015) Carcinoid Tumor of the Cecum Presenting with Acute Appendicitis: A Case Report. Chirurgia, 2, 171-174.

[9] Buyukbese Sarsu, S., Ucak, R., Buyukbese, M., et al. (2013) Unusual Histopatholog- 
ical Findings in Childhood Appendectomy Specimens. Indian Journal of Surgery, 77, 594-599. https://doi.org/10.1007/s12262-013-0934-0

[10] Akbulut, S., Tas, M., Sogutcu, N., Arikanoglu, Z., et al. (2011) Unusual Histopathological Findings in Appendectomy Specimens: A Retrospective Analysis and Literature Review. World Journal of Gastroenterology, 17, 1961-1970. https://doi.org/10.3748/wjg.v17.i15.1961

[11] Altun, E., Avci, V. and Azatcam, M. (2017) Parasitic Infestation in Appendicitis. A Retrospective Analysis of 660 Patients and Brief Literature Review. Saudi Medical Journal, 38, 314-318. https://doi.org/10.15537/smj.2017.3.18061 